\title{
Psychic Pain in Chronic School Failure/Learning Disabilities: Evidence from a Projective Technique
}

\author{
Dimitris S. Nikolopoulos* and Kalliopi Chatira*
}

\author{
University of Crete, Faculty of Social Sciences, Department of Psychology, Crete, Greece
}

\begin{abstract}
The present study attempts to investigate the existence of psychic pain in young learners experiencing chronic school failure/learning disabilities. Using a projective technique, the participants were asked to express the thoughts, feelings, dreams and wishes of an 'imaginary' child of their own age. LD individuals: a mentioned terrifying nightmares, and b. did not 'admit' their LD, even though in subsequent questions the majority admitted a projection of their own thoughts and feelings onto the 'imaginary' child. A high proportion of 'average/good' academic performance individuals answered more positively. The response pattern of LD individuals in our projective task not only reveals the magnitude of the psychic pain experienced by LD individuals but also offers a unique depiction of the way in which each of these individuals experience the psychic pain. The feeling of 'helplessness' stemming from chronic LD, combined with other related negative experiences during the sensitive years of personality development, add up to severe psychological pressure like that described in the psychological trauma literature.
\end{abstract}

Keywords: Chronic school failure, learning disabilities, projective techniques, psychic pain, trauma.

\section{INTRODUCTION}

Research evidence reveals that chronic school failure/learning difficulties may exercise a decisive influence on the emotional condition and the psychological balance of the individual. More precisely, individuals with LD tend to have a negative self concept [1]; demonstrate increased levels of anxiety [2]; emotional imbalance [3]; psychological problems [4]; depression [5, 6]; and suicidal ideation [7].

The presence of psychological consequences in the LD individual is even more apparent and revealing in the few existent ideographical reports. A dominant element in the interviews and personal narrations of LD individuals is the feeling of being 'different', as well as feelings of inadequacy, shame, humiliation and social isolation [8-11]. The intensity of those feelings is such that some researchers refer to a. the existence of a 'gap' between the world of people with a normal development and the world of LD individuals [11]; b. the notion of 'stigma' that such difficulties may give rise to [10]; and c. the existence of 'psychological trauma' $[8,10]$. In this latter case, there is a reference to a particular type of trauma, that of 'LD trauma' [10] / 'cumulative trauma' [12]. According to this claim, the experience of individuals suffering from chronic learning difficulties may, on the one hand, be traumatic and call into question fundamental qualities of the self, but on the other hand, "not constitute a clinical diagnosis of trauma as the LD individuals have not encountered or witnessed a threat of death or physical harm" [10], (p. 377).

Another observation derived by studying the data more carefully, is that even though in the existent ideographical

*Address correspondence to these authors at the University of Crete, Faculty of Social Sciences, Department of Psychology, Crete, Greece; Tel nos.: +3028310 77538, 28310 77522; Fax: +302106990653;

E-mails: nikolopoulos@uoc.gr and chatirak@uoc.gr reports the 'humiliating' feelings mentioned are expressed by the majority of the individuals experiencing them [8-10, $13,14]$, in research studies using self-reporting psychometric scales, the percentage of LD participants reporting intense emotional distress tends to be lower [5].

Based on the above mentioned observations, the present study makes an attempt to examine the inner thoughts and feelings of children experiencing chronic school failure/learning disabilities and if possible to depict, in a rather unique and personal way, the way in which psychic pain is experienced by them. It varies from the already existent research in the field in that the participants were not previously diagnosed adults, but elementary school children experiencing learning difficulties at the time of their assessment. This fact along with the use of projective techniques, such as the one described in the present article, was expected to provide us with a more realistic overview of the emotional experiences of LD individuals and of the possibility of an existing psychological trauma, than an approach based on adult narrations of childhood experiences would.

A projective technique was devised according to which every examinee was required to guess how an 'imaginary' person of the same age would most probably orally answer 12 questions referring to the 'imaginary' person's emotions, thoughts, dreams and desires.

According to the 'philosophy' characterising that type of projective techniques, when asked to respond spontaneously to what the 'imaginary child' would think or feel, the individual would have to respond by essentially 'projecting' his/her own thoughts and emotions. Given that most of the questions of our newly devised technique focused on the school learning experiences, in essence the source of their distress, our hypothesis was that the responses of LD indi- 
viduals to the questions aimed at 'challenging' their 'unconscious' through the process of the projective procedure would be particularly negative and that their responses would offer us a "window" onto the unique way in which each individual internalizes/experiences psychic pain.

\section{METHOD}

\section{Participants}

Sixty eight (41 boys and 27 girls) middle-class native speakers of the Greek language participated in the present study. All were attending elementary schools in the urban area of Rethymnon, Crete. From the initial corpus of the school population ( 305 children) it was possible to recruit 68 participants, after the exclusion of bilingual children, children with no regular attendance, children attending the first grade, children with low IQ, or children exhibiting isolated academic and/or cognitive deficits.

Based on an operational definition of learning disability [15], participants were characterized 'poor performers' (LD group) or as 'average/good' school performers, depending on their performance on a number of tasks assessing a) their non verbal intelligence, $b$ ) various aspects of their academic performance and c) their cognitive and (meta)cognitive/ linguistic functioning (see Table 1).

On the basis of their performance on all these tasks, it was possible to recruit 55 participants with learning disabilities (i.e. participants exhibiting both academic and cognitive deficits but not low IQ: our experimental group) and 13 participants with average/good performance (i.e. participants with average/good performance on all academic, cognitive and meta-linguistic tasks: our control group).

At the time of the assessment, 13 of the participants were in Grade 2 with a mean age of 92.7 months (range: 86-103); 16 were in Grade 3 with a mean age of 102.9 months (range: 97-115); 9 in Grade 4 with a mean age of 116.4 months (range: 111-123); 10 in Grade 5 with a mean age of 128 months (range: 122-149); and 20 in Grade 6 with a mean age of 141.9 months (range: 134-168).

Apart from the above-mentioned tasks assessing academic and cognitive functioning, our test-battery also included a variety of tasks assessing their inner thoughts and feelings and/or their psychological condition with a variety of self-reporting psychometric scales (e.g. Children's Depression Inventory: Kovacks, [16]; Self-Perception Profile for Children: Harter, [17], etc), or projective techniques (e.g. drawings, the 'imaginary child' technique). However, since this article focuses on the psychic pain emanating from chronic school failure, the results obtained from only one of the projective techniques used in this study, that of the 'imaginary child', will be described in this article.

\section{The 'Imaginary Child' Technique}

This particular technique represents an attempt to construct a projective tool aimed at the evaluation of the emotional state of 6-12 year-old children. It was constructed based on the general principles followed in the construction of projective tools of the 'complete sentence' type like the ones of Rotter [18]. Its goal is a comprehensive investigation focusing on the emotional profile and the experiences that a child derives from his/her learning at school. The testing tool has 12 main items, that is 12 complete sentences/ questions requiring the spontaneous response of the participant so that he/she should provide his/her 'view' on the matter put forward by each item/sentence, as well as 6 complementary items that aim at the collection of additional material regarding each participant's self-references.

The $1^{\text {st }}$ sentence/question "A child named [...] returned home from school and was very happy. Why? " allows for the child's smooth introduction into the testing procedure.

The $2^{\text {nd }}$ sentence "One day in class the child saw the other children watching him/her. Why?" aims at the verification or the reversal of the positive feelings or the positive disposition of the previous sentence.

The $3^{\text {rd }}$ sentence "Once he/she entered his/her class feeling very sad. What do you think was the matter?" aims to introduce the child more dynamically into the school environment and especially the classroom.

The $4^{\text {th }}$ ("One day at home his/her mother told him/her off. Why?") and $5^{\text {th }}$ ("Once his/her father argued with him/her. Why?") sentences attempt to explore the child's relationship with his/her mother and father in issues directly related to school.

Sentence 6 "One day this child saw his/her mother talking with the teacher. What might they be talking about?" and sentence 7 "One morning the teacher called for the child's parents to come to school. What might the teacher tell them?" directly explore the child's self-perception and selfcontrol as a pupil and its relationship with the teacher. They also attempt to investigate the child's view regarding the perception of others (teachers or parents) about him/herself, the child's attitude and behaviour toward situations faced at school, his/her school experiences, as well as possible threats to the child's self-image. Those two sentences are phrased in a particularly stimulating manner in order for the participant to project his/her possible inner conflicts which exist as unconscious material. On a more realistic, that is a more conscious level, they aim to facilitate the expression of the participant's demands and complaints, as well as facilitate a depiction of the child's 'ideal self' along with the possible defense mechanisms that might be mobilized (denial, overcompensation, sublimation). For those reasons, these two sentences, in combination with the one referring to the imaginary child's dreams and desires, were considered as the most appropriate for the detection of possible psychological trauma; the subsequent analyses focused especially on those sentences.

The $8^{\text {th }}$ sentence "One afternoon, the child was very angry. What might have happened?" explores the self-image and the feelings expressed in the two previous sentences. Here we can detect again the child's school related experiences.

The $9^{\text {th }}$ sentence "One night this child had a dream that woke him/her up. What do you think was in that dream?" allows the expression of feelings through the symbolic "language' of dreams. This symbolic discourse is particularly 'talkative', already offering an interpretation of the unprocessed experience(s). The child's attempt to narrate a dream facilitates the overcoming of possible resistances and the verbalization of desires, complaints, troubles as well as those 
Table 1. Descriptive statistics - testing domains and individual tests.

\begin{tabular}{|c|c|c|c|}
\hline Number of pupils & Total & 13 & 55 \\
\hline Age & Mean (sd) & $118.7(17.8)$ & 117.7 \\
\hline \multirow{2}{*}{ Intelligence } & Range: & $4-8$ & $4-8$ \\
\hline & Test Used: & \multicolumn{2}{|c|}{ Raven's Standard Progressive Matrices ${ }^{4}[19]$} \\
\hline \multicolumn{4}{|c|}{ Overall Academic Achievement (Tests used: Group a) } \\
\hline \multicolumn{4}{|c|}{ Overall (Meta)cognitive Achievement (Tests used: Group b) } \\
\hline & Mean $^{2}$ SS (sd) & $73.9(1.58)$ & $111.8(1.9)$ \\
\hline & Range & $71.5-77.5$ & $108.5-115$ \\
\hline \multicolumn{4}{|c|}{ Tests used to assess Academic Achievement. (Group a): } \\
\hline \multicolumn{2}{|c|}{$\underline{\text { Reading ability ( } 2 \text { tasks): }}$} & \multicolumn{2}{|c|}{ Reading Real words ${ }^{3}$, Reading Pseudowords ${ }^{3}$ (Accuracy \& Speed) [20] } \\
\hline \multicolumn{2}{|c|}{ Spelling ability ( 2 tasks): } & \multicolumn{2}{|c|}{ Spelling real words ${ }^{4}$, Spelling the months of the year ${ }^{4}[20]$} \\
\hline \multicolumn{2}{|c|}{ Arithmetic ability (1 task): } & \multicolumn{2}{|c|}{ BAS - Basic Number Skills subtest $t^{4}[21]$} \\
\hline \multicolumn{4}{|c|}{ Tests used to assess Cognitive Achievement (Group b): } \\
\hline
\end{tabular}

${ }^{1}$ Raven classifications: Superior $=\mathbf{8}$, Above II $+\mathbf{= 7}$ Above $=\mathbf{6}$, Average III $+=\mathbf{5}$, Average III- =4, Below =3, Below IV- = 2, Impaired=1

${ }^{2}$ Standardized scores: mean $=100$ and sd $=15$,

${ }^{3}$ Individual testing

${ }^{4}$ Group testing

representations derived from any source of anxiety and conflict in order to reveal something of the child's present or past psychological condition.

Sentences 10 "Once the child saw his/her parents quarreling. For which reason might they be quarreling?" and 11 "Another time his/her parents got mad at him/her. Why?" explore the relationship between the parents and the relationship between the child and his/her parents respectively, both in the family and the school environments.

Finally, the $12^{\text {th }}$ sentence "That child had a major desire. What might that be?" aims to explore the child's desires on a realistic level, but also the deeper wishes/desires and/or complaints. The content of this sentence allows the child to express and externalize in the form of a wish/desire or complaint what unconsciously troubles him/her. It is deliberately placed at the end of the list because based on this sentence we could psychodynamically verify and assess the dream content, also representing unconscious unfulfilled desires.
With a set of complementary sentences (Sentences $\mathrm{N}^{\mathrm{o}} 13$ $\mathrm{N}^{\mathrm{o}} 18$ ), the testing technique also provides the examiner with the opportunity to obtain an insight regarding a. each child's level of conscious realization regarding the overall procedure; $b$. the conscious representations of the 'ego' and the 'ideal ego', especially through Sentence 16 "was this child in any way similar to you?"; and c. a reality indicator, through Sentence 17 "in which way was he/she similar to you?" and 18 "In which ways was he/she not similar to you?" in order to manifest the realistic element in the response content and the control of the child's emotionality or the obstruction of the child's feelings because of conflicts, inhibitions and guilt.

\section{PROCEDURE}

Since this research project was a 'pilot' investigation of the emotional condition of individuals with chronic learning difficulties, we tried to include pupils from all the grades of elementary school, with the exception of children attending 
$1^{\text {st }}$ Grade. Not being able to include all the children of each class, we asked the teachers of the participating classes to suggest 10 children with poor school performance (including individuals with an official diagnosis of learning disabilities) and another 10 with an average/good performance. An effort was made to test as many of those children as possible. In some cases that was not feasible and this explains why the total number of participants was 68 .

Each participant was tested, both individually in two sessions, each lasting for approximately two hours, and in a group, for the assessment of non-verbal intelligence, spelling and arithmetic skills and the administration of self-reporting scales (see Table 1). The individual assessment took place in a quiet room inside the school building, while the group testing took place in the participants' classrooms. Tests were administered in random order. Parental consent forms were signed before the initiation of the procedure.

\section{RESULTS}

Given that even a brief reference to the way in which the LD and the control participants responded to each of the test's sentences/questions would make this article too long, we chose to group the responses to the most relevant to the manifestation of psychic pain/trauma items of the testing tool, such as the ones referring to: a. the school (Sentences $\mathrm{N}^{\mathrm{o}} 6$ and 7); b. the dream attributed to the 'imaginary child' (Sentence $\mathrm{N}^{\mathrm{O}}$ 9); c. the 'imaginary child's' possible desire (Sentence $\mathrm{N}^{\mathrm{O}} 12$ ) ; and, $\mathrm{d}$. the responses regarding the possible similarity between the 'imaginary child' and the participant (Complementary Sentences $\mathrm{N}^{\mathrm{o}} 16,17,18$ ).

Participants' responses to these items were expected to be revealing of their negative, if not traumatic, experiences with learning; of the magnitude of the psychic pain induced by the cumulative impact of every-day school failure and humiliation and personal frustration, not only at school but also at home. The psychic pain experienced by the learning disabled was thought to be rather idiosyncratic because of the inability of these individuals to defend themselves against the source of their anxiety, pain, frustration and humiliation being forced, in this way, to endure their everyday ordeal unprotected and in silence.

\section{A. Summary of Responses Given to the Main Sentences Regarding Learning and School $\left(\mathrm{N}^{0} 6\right.$ \& 7)}

Sentence $\mathrm{N}^{\mathrm{O}} 6$ "One day this child saw his/her mother talking to his/her teacher. What would they be talking about?" and Sentence $\mathrm{N}^{\circ} 7$ "One morning the teacher asked the child's parents to come to school so he/she could talk to them. What would the teacher say to the parents?" focused on the participant's feelings towards school learning. Since one of the most common reasons a teacher asks a child's parents to come to school is to talk about the child's school performance and behavior, it was expected that those two sentences would cause significant emotional tension for the LD participants and that they would simultaneously 'challenge' any 'repressed' traumatic, learning related experiences. Thus, the way that each participant responded would be suggestive of the level of their psychic pain experienced day-by-day, of their traumatic experiences in school, as well as of the manner that the respective participant was trying to 'handle' it.
The results revealed very significant variations between the responses provided by the LD participants and by those with an average/good performance. More precisely, of the 55 LD participants, 67\% (37/55) avoided mentioning, in both sentences, a possible learning problem of the 'imaginary child' as being the reason for the teacher talking to the mother or having asked the parents to come to school. An additional $28 \%(15 / 55)$ reacted in a similar way to either one of the sentences, but referred to difficulties in the 'imaginary child's' school performance in the other. The percentage of LD participants referring to learning problems in both cases was just 5\% (3/55). We should also mention the fact that, despite their diagnosed learning difficulties, a high percentage $(49 \% ; 27 / 55)$ not only did not refer to the 'imaginary child' having learning problems, but responded that the teacher wanted to inform the 'imaginary child's' parents that he/she was "doing very well" academically and in some instances that he/she was either "perfect" or "one of the best in class".

Those responses signify typical examples of 'overcompensation'. Furthermore, certain responses of the LD participants like "needs help in studying" (ID 18), "tries but more effort is required" (ID 16), "he is doing well, he is smart" (ID 59), "she needs help but she is smart and she will make $i t$ " (ID 19), reveal both the anxiety that those participants were experiencing and the effect that their learning difficulties had upon them. In addition, we should underline the obvious effort of many participants to 'deny' the existence of difficulties by providing responses which clearly did not represent reality. The following responses regarding why the teacher called for the parents are characteristic: "the child had a problem in her artwork because her scissors were not functioning properly" (ID 60); "because they would go on a field trip and there wouldn't be any classes" (ID 7). Finally, a more careful study of the responses which overall or partially do not refer to the existence of difficulties, revealed the tendency of $50 \%$ of the LD participants to attribute their shortcomings either to circumstantial causes i.e. "she had not studied/was unprepared for class on a certain day" (IDs 28, 66,32 ), or to a non-permanent weakness/disability i.e. "does not pay attention" (ID 15); "does not try" (ID 63); "goes unprepared because she is bored" (ID 9); "does not participate in the class" (IDs 35, 53); "did not complete a written assignment" (ID 25). We believe it is not a coincidence that a high percentage of those same participants had responded to the other of the two sentences along the general lines that the "imaginary child' "performed very well at school".

\section{B. Summary of Responses Regarding a Possible Dream of the 'Imaginary Child' (Sentence $N^{\circ}$ 9)}

Having 'attacked' the unconscious with the previous sentences/questions regarding learning $\left(\mathrm{N}^{\mathrm{O}} 6\right.$ and 7 but also $\mathrm{N}^{\mathrm{O}} 1$, $2,3,4)$, we believed that the responses to sentence/question $\mathrm{N}^{\mathrm{o}} 9$ ("what dream might have woken the child up one night?") would be unconsciously connected to learning and thus especially revealing of any 'repressed' traumatic experiences and emotions. So, if our hypothesis that the effect of intense criticism, continuous and immense psychological pressure, the feeling of being 'different', humiliation and generalized rejection is so determinant for individuals experiencing severe learning difficulties is correct, then their re- 
sponses to this particular question would not only be especially negative but also especially revealing.

Indeed, the overall results confirmed our claim. $95 \%$ of the individuals experiencing difficulties at an academic/cognitive level mentioned that the dream that the 'imaginary child' had was a terrifying nightmare. More precisely, $30 \%$ of the LD participants mentioned dreams in which the 'imaginary child' was either murdered by a villain or was facing a threat of serious injury i.e. "a bad, very bad clown wanted to kill her" (ID 50); "a monster stabbed him" (ID 1); "the buggy-men got him and slaughtered him" (ID 59); "Death wanted to take him; he woke up after he was taken" (ID 60); "he was thrown into hell" (ID 32). Another $16 \%$ mentioned dreams in which a member of the "imaginary child's' family was being killed i.e. "the little child killed his mother and the child was watching; the father held a knife and the little child was crying" (ID 62); [the "imaginary child" saw in her dream] "that her mother died; I saw that my aunt was biting me, biting me, biting me..." (ID 9); "two men in black came and wanted to take his mother away" (ID 68). 16\% mentioned an undefined nightmare or ghostly dreams. Especially interesting were the 'imaginary child's' dreams mentioned by $22 \%$ of the LD individuals.

Those dreams referred to learning and learning associated problems: [the 'imaginary child' saw in the dream] "that he was inside studying all day" (ID 4); "that the teacher told him to leave school and that he wouldn't be accepted in any school" (ID 63); "that he was at school and the teacher had taken him to the principal" (ID 55); "that he couldn't answer a question in history and the teacher threw him out of class" (ID 67); "that the teacher doesn't give her good grades" (ID 43); "remembered that he hadn't done something required for school" (ID 15) etc. The percentage of LD participants who did not mention the 'imaginary child' having had a nightmare was significantly low (5\%). These individuals responded that: [the 'imaginary child' saw in the dream] "mum and dad biting each other; doing something bad in bed (nasty)" (ID 56); "his mother had taken away his gameboy and kept it" (ID 61); "he had grown up and became what he wanted: a singer" (ID 65).

The responses of the average/good participants were also particularly interesting. Confirming our hypothesis that a reference to nightmares is not coincidental but characteristic of individuals experiencing intense emotional pressure regarding learning was the fact that $46 \%$ of the average/good participants generally attributed nice dreams to the 'imaginary child' i.e. his/her granny knitting; the desire for the birth of a baby sister; dreaming about the future; playing with friends; or dreams with an indifferent content like "he saw his parents fighting because his father was tense and he took it out on his mum". Nevertheless, the remaining $56 \%$ of the control group participants mentioned that the 'imaginary child's' dream was a nightmare, similar to the nightmares mentioned by the LD participants.

In order to investigate whether those particular members of the control group had a specific reason which 'caused' their responses, we had to refer to their responses in the other 'imaginary child' sentences/questions, as well as to their responses in a questionnaire assessing their learning related feelings (Reference containing identifying information - to be added). The questionnaire responses revealed that the majority of the above mentioned participants did not feel proud of themselves, were not satisfied with their classmates, while some felt the need for more assistance at school (IDs $10,14,39,41)$; that their teacher's comments were not positive (IDs: 10, 14, 39); that their grades were unfair (IDs: 14, $39,41)$; that school was a source of anxiety (ID: $14,33,39$ ) etc. (See -Reference containing identifying information/to be added-for more details).

The investigation of the responses of those particular participants to the other sentences/questions in the projective part of the assessment was also revealing of their learning related feelings. In many cases, the responses confirmed the existence of demanding school performance targets as well as a general uneasiness regarding their overall academic status; these views were shared between the participants and their parents. The participant with ID 10, for instance, responded to why the 'imaginary child' entered her class feeling sad (Sentence $\mathrm{N}^{\mathrm{o}} 3$ ) saying that "she had all her written assignments just signed and not graded by the teacher because they were not completed"; that when the teacher was talking to the 'imaginary child's' mother (Sentence $\mathrm{N}^{\mathrm{o}} 6$ ) the teacher said that "she was only occasionally good in class"; and that the reason why the teacher had called for the parents (Sentence $\mathrm{N}^{0} 7$ ) was because "she had gone to school without having studied her arithmetic assignments".

The responses of the participant with ID 661 followed the same line of thought. In the sentence asking why his parents were once angry at him (Sentence $\mathrm{N}^{\mathrm{o}} 11$ ) he responded "because I got 8 instead of 10 in mathematics"; in the sentence referring to the possible similarities between himself and the story of the 'imaginary child' (Sentence $\mathrm{N}^{\mathrm{o}} 16$ ) he responded that the 'imaginary child" "got into serious trouble with his mum because he was not a good pupil". Equally revealing were the responses provided by the participant with ID 39, whose desire was "to become the best pupil of them all". In the sentence asking why the 'imaginary child' was angry on a certain afternoon (Sentence $\mathrm{N}^{\mathrm{o}} 8$ ), the same participant responded that "he did not get good grades".

Finally, we should refer to the responses provided by the participants with IDs 33 and 14. The desire of the former was for "his parents never to be angry at him again" and this desire may provide a psychodynamic insight into the "imaginary child's' nightmare as mentioned by the same participant, the content of the nightmare being that "someone had killed his parents". The same holds true regarding the responses provided by the latter participant, the one with ID 14. The participant's rivalry with her sister is depicted in the 'imaginary child's' responses to Ss 4, 8 and 11 where the sister is always mentioned as the reason why either the 'imaginary child' or the 'imaginary child's' parents are angry; the participant's low self-image is similarly depicted in the 'imaginary child's' desire to "become tall".

We believe that all the above mentioned results provide adequate evidence supporting our claim, meaning that the participants' responses to the assessment tools administered were not coincidental. Further strengthening our claim is the evidence provided by the analysis of the participants' responses to whether there was any similarity between the 'imaginary child' and themselves. We will refer to that in detail in a subsequent part of this text. 


\section{Summary of the Responses Regarding a Desire of the 'Imaginary Child' (Sentence $\mathbf{N}^{\mathbf{0}}$ 12)}

Sentence $\mathrm{N}^{0} 12$ "That child had a great desire. What desire might that be?" signified another challenge for the unconscious and at the same time, an opportunity for each participant to express his/her inner feelings. Indeed, the responses of many participants, especially the ones with problems in learning, were quite interesting. Attempting a more comprehensive description of the desires mentioned by the participants, we found that the desire expressed by $28 \%$ $(15 / 55)$ of the LD participants referred to toys or some gift that they would like to be offered by the parents, while $33 \%$ $(18 / 55)$ responded that the 'imaginary child's' desire would be to become a doctor, a lawyer, a veterinarian, a teacher, an actor/actress or a singer, a dancer, a football player etc. $16 \%$ attributed to the 'imaginary child' the desire either to become a better pupil, or to have had finished school and not have to study anymore.

The following responses are characteristic: "that she wouldn't have to care about studying nor to care about her parents and that her parents would stop giving her a hard time" (ID 30); "to have finished school" (ID 4); "that he were not taken to the school principal and that he wouldn't yell" (ID 61); "to become a nice kid and a good pupil for ever!" (ID 31); "to become the best pupil in class" (ID 19); "to become a hero" (ID 34), etc. Finally, revealing of the LD participants' feelings were also the responses: "he wished that his parents were nicer toward him, that they would love him and play with him" (ID 66); "that his brother wouldn't beat him up" (ID 62); "that he would see his parents loving each other" (ID 37); "that he had a brother to help him and play with him" (ID 44).

On the other hand, the responses of the control group participants included the 'imaginary child's' desire to become a football player $(38 \% ; 5 / 13)$; to grow up $(15 \% ; 2 / 13)$; to travel to America (1/13). More particular desires were also expressed, like "to become tall", as mentioned previously, "that he would never again get into trouble", "to become a better pupil", "to have just strait As"; "that they were a happy family, never arguing with each other".

\section{Summary of Responses Regarding the Possible Similarity Between the Participant and the 'Imaginary Child' (Sentence $\mathbf{N}^{0} 15$ )}

In order to control whether the responses provided by each participant consisted of a 'projection' of his/her own emotions, we counted on the complementary sentences/questions of the test, especially on those requiring the participant to define any possible resemblance between $\mathrm{him} / \mathrm{herself}$ and the 'imaginary child'. Indeed, $60 \%$ (41/68) of the responses in the complementary items was affirmative, stated either as a plain "yes (we are alike)" or with comments like "(we are) very (similar)", "yes, a little bit", "yes and no". Many participants responded to the question "In which way was he/she similar to you?" (No 17) either in more detail like "yes, he is like me" (ID 48); "almost in everything" (ID 11); "it was all mine" (ID 67); "all were alike" (62); or in more personal terms like "that he is a good pupil and a bad one only in his dreams" (ID 31); "in many things he is like me, my parents also fight with each other and the other kids stare at me and that makes me angry and sad" (ID
68); "in getting into trouble with the parents and in sadness" (ID 49); "he was alike in that he also soiled his hands and had bad dreams" (ID 43). The responses of another 22\% were also interesting. Those participants, even though they had initially responded negatively, in the subsequent questions (i.e. in which ways was the 'imaginary child' similar/ not similar to the participant) seemed to reverse their answers and to plainly admit the existence of a certain similarity between the 'imaginary child' and themselves. The following responses are indicative: "(the imaginary child is similar to me) in studying, in the desire, in everything..." (ID 25); "(we are similar) in the wish (to become the best pupil in class), basically in everything, because what I said was my opinion" (ID 19). Other participants that had initially replied negatively switched from the $3^{\text {rd }}$ to the $1^{\text {st }}$ person during their subsequent responses i.e. "the child's mother talked to the teacher about my progress"; apparently, the respondent was referring to own experiences and feelings.

\section{DISCUSSION}

The present study is part of a longitudinal effort to investigate the psychological consequences of chronic school failure by using various tools. The article at hand focused on the results obtained by a particular projective technique, that of the 'imaginary child', in which the participant was asked to bring to mind an imaginary individual and by responding to a list of questions to express the thoughts, feelings and desires of this imaginary individual. The fact that LD individuals experience intense negative emotions of humiliation, rejection, insecurity, partial identity loss etc. For such an extended period of time during the sensitive and formative years of their childhood, led us to predict that learning in school would be a rather traumatic experience causing high levels of distress and psychic pain. The objective behind the use of the particular projective technique was to enable the children to satisfactorily identify themselves with the 'imaginary child' and so 'overtly' project their unconscious 'pursuers', those related to the difficulties they face.

Indeed, the results generally confirmed our prediction. Despite the fact that in the given procedure participants were asked to respond referring not to personal feelings, thoughts, desires and dreams but to those of an imaginary individual, the majority of the participants unconsciously 'identified' themselves with the imaginary individual, providing responses which expressed their own views and emotions. In most cases of LD individuals, the responses were particularly negative and in our opinion revealing of the extent of the psychological pain they experience as a result of their chronic failure to satisfactorily meet the demands of school, like other children. Especially revealing were their responses as much to the questions related to the 'imaginary child's' dream, as to the other questions aimed at the unconscious 'repressed' feelings related to learning.

In relation to the dream of the imaginary child, $95 \%$ of the participants who were experiencing chronic learning difficulties responded that the dreams were terrifying nightmares, not only in the form of not-related content nightmares (the projected product of the content) but also in the form of nightmares whose content is either trauma-related or threatening and indicative of the presence of guilt [23]. 
Confirming our claim that the reference to nightmares was not coincidental but typical in individuals experiencing intense emotional distress was also the fact that $46 \%$ of the average/good performance participants declared that they had mostly positive dreams (i.e. their granny knitting, the birth of a baby sister, playing with friends etc.), but mainly the fact that the remaining $54 \%$ of the control participants that said they had nightmares were those who in the relevant questionnaire expressed a high level of discomfort towards their classmates, school learning, their ability to deal with school requirements as well as a very low self-esteem.

Therefore, if the claims that: a. dreams are a "royal way to the unconscious" [24]; b. the manifest content of a dream is a defensive 'projection screen' for the latent thoughts related to the conflicts surrounding unfulfilled unconscious desires Siegel, [25]; and c. that nightmares are indirect evidence of a 'repressed' psychological trauma that the individual could not handle [26], stand, then those terrifying dreams mentioned by the participants who experienced intense learning difficulties and in which an explicit reference to either a physical threat or loss of life of the person him/herself or a member of his/her family was made, can be considered indicative of the extent of their emotional distress as well as a 'projection' of the emotional intensity of the trauma they had experienced and probably still experience at school, resulting in chronic distress which might lead to the intensification of the trauma.

The attempt to interpret the content of the manifest dreams of the children in the present study allows us to uncover the dynamics of the intensity of the psychic strain of children with LD who experience long-term personal rejection of their self-image as a result of the attitude and behaviour of others (parents, teachers). The children's identification with the projective trials' imaginary child allows them to project important content from the unconscious. The opportunity to respond to dreams the imaginary child had and which had scared him gives the child the opportunity to express himself in plain terms. It is no coincidence that some of these children's dreams turn into nightmares despite the fact they're not real (these nightmares haven't been experienced in real life). The fact that the child chooses to mention a frightening dream or nightmare is not coincidental either, since he/she is already caught up in the projective process. We know that a dream is the product of a chiefly unconscious process, which creates a mixture of forms and texts, in other words - we could say - an illustration whose linguistic structure allows the subject to reveal his desire, to express his weakness, through the signified chain of his 'dream speech', a particular language. The essence of the dreams, whether they are real or are part of a projective reference, have the same dream content essence, and consequently every form of this illustration, manifest or abeyant, allows us to 'read', as if it were a letter the 'text' (dream content) and for his 'lost tongue' 'trapped speech' to be revealed. This is where the essence of the dream lies. The interpretation of those dreams which were elicited from particular children is based on the connection the 'dreamer' himself makes, in a process of free association, and one can observe familiar good or bad moments or moments of fear from his past. Freud 1920/1993 [27], explaining the way dreams function, sheds light on the dividing line between them and reality the representation returns to its sensory form, the object's perception blends with the representation, in other words what is termed 'primary processing of the reciprocation of the dream' occurs.

Having adopted a psychoanalytic approach, we consider those particular dreams to be highly significant on a symbolic level. Into these symbolic nightmares the child represses his/her unprocessed emotions, his/her discomfort and anxiety in the presence of the perceived threat [28]. Siegel and Bulkeley, [29] for instance, relate nightmares, when occurring on either a realistic or an imaginary level, to the child's psychological turmoil, that is to factual traumatic experiences, stressful events, loss, and psychological causes such as constant pressure and distress. Seen from this angle, the dreams mentioned by many LD participants in the present study in which someone is killing them (e.g. a monster, the buggy man, the terminator, Death etc.), slaughtering them, throwing them into hell etc., may be considered to be a possible reflection of the individual's unconscious effort to 'exterminate' him/herself on an imaginary level; the self is in this case experienced as the source of the intense feelings of disappointment, humiliation, depreciation and rejection. In a similar way, nightmares where the participant's whole family or a member of the family is being killed (e.g. the mother or the father) may be considered to be reflecting the individual's 'unconscious' effort to 'eliminate' the source of anxiety, punishment and depreciation, in an attempt to protect his/her "ego".

This attempt to eliminate, on a symbolic level, the persons accounted responsible for the experienced distress signifies an effort to prevent the individual's loss of self-esteem and retain the healthiest 'self-image' possible, despite whatever takes place in his/her everyday reality. Characteristic of the magnitude of the perceived threat and the agony experienced by the LD individuals is a child's nightmare in which, as the child describes it, "Death wanted to take me away and I woke up after he had taken me" (ID 60). This threat appears again in the participant's next answer (Sentence $\mathrm{N}^{\mathrm{o}} 11$ ) pointing out that the parents were angry at him "for his bad grades". Another participant (ID 24) unconsciously 'kills' his father in his dream in which "they killed my dad" since his father gets angry with him (Sentence $\mathrm{N}^{\mathrm{o}} 11$ ) because the boy hadn't "done his homework". Thus, for an LD child, bad grades are a nightmare.

Golse, [30] as well as Houzel, [31] believe that the anxiety experienced on a symbolic or realistic level during a nightmare in young children may only be explained through its manifest content. Even though really connected with its covering representations, anxiety stems from a different source. From this point of view, the dream anxiety coincides with the anxiety and restlessness caused by the traumatic experience. This is confirmed by the dreams and desires of the participants in the present study. We can see that, through the manifest content of their dreams and nightmares, children express the very despair caused by the pressure and/ or the rejection coming from the parental figures for possible issues concerning school and learning. For instance, the content of the nightmare "his mum was bad and so was his dad; they were very firm, didn't let him play; he had to study a lot..." expresses the child's (ID 66) psychological pain at the loss of its autonomy and self-respect (the need to play is bypassed in order to study) but also the loss of the protective 
mother (she becomes bad by wanting him just to study). This is confirmed by the desire following the nightmare: "I wished his parents were kinder to him! That they would love him and play with him". This particular child hopes to gain his parents' love and acceptance. Equally revealing is the content of the following dream: "he was at home studying all $d a y$ " and the subsequent desire confirming the pressure that is apparently unbearable "that he had finished school" (ID 4). The distressful feelings caused by the constant pressure experienced cumulatively by the child in the school environment but also from the 'significant others' in his/her life can be clearly observed in the content of the nightmares attributed to the 'imaginary child' by a number of participants: e.g. "the teacher told him to leave school and that he wouldn't be accepted in any school" (ID 63); "that he was at school and the teacher had taken him to the principal" (ID 55).

Siegel, [25] points out that nightmares often accompany the emotional pain of a traumatic event that an individual experienced or constantly experiences during his/her life course. But if a trauma that occurred during childhood is repressed, constant or particularly painful, then the dream's content reflects either the emotional intensity of the trauma, or the psychological distress that might persist in a repetitive compulsion until the trauma is finally represented in consciousness in a symbolic way and thus, can be healed. The repetition of the nightmare content in fantasy apart from reality, may drastically contribute to the catharsis through the normalization of fears and anxiety, the desensitization of the real 'nightmare', meaning the painful emotional arousal, and its disturbing content [32]. The dreams and desires attributed to the 'imaginary child' by some participants are quite representative of this process. One of the LD participants (ID 40), for instance, 'regards' as a nightmare "that the teacher doesn't give her good grades" (Sentence $\mathrm{N}^{\mathrm{0}} 12$ ), while the desire expressed "I want to become a teacher" signifies an 'identification with the aggressor' in order not to become a 'fugitive'. Thus, along with the realization of the cause of the ego's narcissistic trauma (that the teacher does not give good grades), occurs the drastic, possibly therapeutic, ego defense of overcompensation (to become a teacher).

Freud, [24, 27] maintained that each dream is the fulfillment of a desire. This view was also held by contemporary psychoanalysts $[28,33]$. The fulfillment of a desire does not necessarily signify the pursuing of pleasure. Nevertheless, this idea of the fulfillment of a 'secret' desire through a dream remains central in classical Freudian psychoanalysis. On the other hand, theoreticians like Alan Siegel [19], accept the unconscious significance of dreams which are 'reflected' more as a desire fulfillment. That is, dreams are useful and purposeful insinuations for the amelioration of the quality of life and they might safeguard a distance from selfcatastrophic attitudes. There were strong indications of this latter view in the participants' dream contents and desires in the previously mentioned references. For instance, the manifest content of the dream "she had studied and was a very good pupil" (ID 30) appears as a defensive screen for the projection of the latent thoughts which are connected to the conflicts surrounding the unfulfilled and unconscious desires: "that she wouldn't have to care about studying nor about her parents and that her parents would stop giving her a hard time". An indirect indication of the existence of a 'repressed' psychological trauma in LD children is also shown in the realization of the bad dream "that he wasn't a good pupil and that he was naughty" which reflects the desire "to become a nice kid and a good pupil forever!" (ID 31). Similarly, in the case of the participant with ID 8 the attributed bad dream was "that she wasn't a nice pupil" whereas the desire "I want to become a doctor" allows her to handle the trauma in a more positive way. The same holds for the dream of the participant with ID 43 "she got a lot of $B s$ " which reflects the constant disappointment experienced because of bad grades; nevertheless, her desire "to become the best pupil of them all', counterbalances her low selfesteem. These desires are intensified by daily events and counteract the ego defense mechanisms (the dream process). A conflict might follow, in the form of a sleep 'disturbance' as Freud argued. This conflict may enter the dreamer's unconscious unless it is resolved by a compromise: forbidden desires will be represented in the dream content but only if transformed by the primary mechanisms of condensation ("he was thrown into hell"/ID 32); displacement ("he had nicer peers and thus his performance was better" / ID 26); and symbolism, as in references to "ghosts" and "thrillers". Therefore, the manifest contents of the dreams consist of a defensive alteration of the real or latent thoughts of the dreamer.

Another interesting element that emerged from the answers of the participants in the trial was the way they reacted to the questions related to the reason behind the visit of the parents of the imaginary child to the school. More specifically, when the LD participants were asked what the 'imaginary child's' parents might be talking about with the teacher or why the teacher had asked them to visit school, only $5 \%$ answered in both items that the main reason they were talking to the teacher was their child's poor school performance. Another $25 \%$ of the LD participants responded in a contradictory manner, accepting the existence of mostly 'temporary' difficulties in just one of the items. An impressive $75 \%$ responded that the content of the conversation between the teacher and the 'imaginary child's' parents or the reason why the teacher had requested the parents' school visit, not only had nothing to do with the child's learning difficulties, but in many cases that the teacher's intention was to inform the parents of their child's progress and good academic performance. We believe that these data express the LD participants' unconscious attempt to 'deny' the existence of their difficulties which, also according to the results obtained by the questionnaire assessing the participants' thoughts and feelings towards learning and their general school presence, was a source of intense psychic pain for the majority.

We believe that the results of the present study are fully consistent with the findings of other researchers in the field which reveal the significance of a child's school experiences not only for the development of an academic self concept [34], but also for the general perception and evaluation that a child develops for him/herself [35]. The present results also seem to support the claims of those researchers who believe in the existence of a particular psychological trauma in LD individuals $[8,10]$, which even though not substantiated clinically (since it does not include a threat against the individual's life) seems to have significant psychological consequences, relevant to the ones of officially documented trauma. Furthermore, we believe that the present findings 
contribute to the enrichment of our knowledge in the field. The fact that the population addressed was still at school during the assessment allowed for a more realistic depiction of the psychological trauma possibly experienced by an LD child, since this depiction takes place at a time when the trauma is experienced as a stressful event per se and not as post-traumatic stress [36].

We believe that our results offer a more realistic \& vivid depiction of psychic pain than what the responses to a simple questionnaire which didn't facilitate the child's introduction to the projective procedure (mobilizing the identification mechanism), could have recorded, due to the use of the 'imaginary child' projective technique. Actually, we think that this particular assessment tool, by not requiring direct self-reference, drastically reduces the possibility of activating the individual's ego defense mechanisms and therefore the conscious alteration of the responses; thus, it offers the researcher a 'primary' and 'clear' picture of any possible 'repressed' traumatic experiences [37, 38]. We should note, however, that the activation of 'defensive' mechanisms was nevertheless obvious in the 'imaginary child' projective assessment. As already mentioned, a significant number of LD participants not only manifested the tendency to 'deny' the existence of their academic/cognitive difficulties, but also used a number of other defense mechanisms: condensation, displacement, overcompensation. In theory, the ego of those individuals attempts to mobilize all its powers at a primary level, in order to defend itself at a secondary level [33]. This defense would prevent the overflowing of anxiety into consciousness and set the foundations for more positive emotions able to establish at least a temporary 'symmetry' between the internal and the external threat. Maybe those two parameters of our approach could explain why in our study the percentage of LD individuals reporting intense emotional distress was much higher (near 98\%) than the one mentioned in relevant research studies which have used self-reporting scales $[5,39]$.

In summary, we believe that the results of the present study strongly support the view that the experiences of individuals with chronic learning difficulties so profoundly affect those individuals' self-image and self esteem that the notion of 'LD trauma', put forward by McNulty [10] is absolutely consistent with the extent of the psychological pain depicted in the responses of the LD individuals of the present research project. The responses and the particular way the individuals with LD verbalized their psychic pain in their responses to the research effort's questions aimed at the imaginary child reveal that this psychic pain is related to the feelings of insufficiency caused by the chronic learning difficulties, the criticism usually following them, as well as the social rejection and isolation often experienced by LD individuals. It is possible that the relatively small number of participants - especially in the control group- as well as the use of a rather limited number of different psychometric tools might have limited the validity of the above statement. Nevertheless, the high degree of constancy in the occurrence of serious psychological distress indications among LD participants in all our projective tools strengthens our belief that our hypothesis should be further investigated. We intend to proceed in this investigation even more systematically by simultaneously distributing to a given sample still other psychometric and projective tools.

\section{CONFLICT OF INTEREST}

The authors confirm that this article content has no conflict of interest.

\section{ACKNOWLEDGEMENTS}

Declared none.

\section{PATIENT'S CONSENT}

Declared none.

\section{REFERENCES}

[1] Stanovich PJ, Jordan A, Perot J. Relative differences in academic self-concept and peer acceptance among students in inclusive classrooms. Remedial Spec Educ 1998; 19: 120-5.

[2] Hoy C, Gregg N, Wisenbaker J, Manglitz E, King M, Moreland C. Depression and anxiety in two groups of adults with learning disabilities. Learn Disabil Q 1997; 20: 280-91.

[3] Masi G, Brovedani P, Poli P. School failure in early adolescence: The psychopathological risk. Child Psychiatry Hum D 1998; 29: 127-40.

[4] Greenway P, Milne L. Relationship between psychopathology, learning disabilities, or both and WISC-III subtest scatter in adolescents. Psychol Sch 1999; 36: 103-8.

[5] Health NL, Ross S. Prevalence and expression of depressive symptomatology in students with and without learning disabilities. Learn Disabil Q 2000; 23: 24-36.

[6] Maag JW, Reid R. Depression among students with learning disabilities: assessing the risk. J Learn Disabil 2006; 39(1): 3-10.

[7] Hayes ML, Sloat RS. Preventing suicide in learning disabled children and adolescents. Acad Ther 1988; 24: 221-30.

[8] Cohen J. Learning disabilities and psychososial development in childhood and adolescence. Ann Dyslexia 1986; 36: 287-300.

[9] Hellendoorn J, Ruijssenaars W. Personal experiences and adjustment of dutch adults with dyslexia. Remedial Spec Educ 2000; 21(4): 227-39.

[10] McNulty MN. Dyslexia and the life course. J Learn Disabil 2003; 36(4): 363-81.

[11] Orenestein M. Smart, but stuck: what every therapist needs to know about learning disabilities and imprisoned intelligence. New York: Haworth 2000.

[12] Khan M. The concept of cumulative trauma. Psychoanal Stud Chil 1963; 18: 286-306.

[13] Gerber PJ, Reiff HB. Speaking for themselves: Ethnographic interviews with adults with learning disabilities. Ann Arbor: University of Michigan Press 1991.

[14] Reiff HB, Gerber PJ, Ginsberg R. Exceeding expectations: Successful adults with learning disabilities. Austin, Texas: PRO-ED 1997.

[15] Kavale KA, Forness SR. What definitions of learning disability say and don't say: a critical analysis. J Learn Disabil 2000; 33(3): 23956.

[16] Kovacs M. Children's depression inventory (CDI) manual. North Tonawanda, NY: Multi-Health Systems 1992.

[17] Harter S. Self-perception profile for children. Denver: CO: University of Denver Press 1988.

[18] Rotter JB, Lah MI, Rafferty JE. Rotter Incomplete sentences blank. $2^{\text {nd }}$ ed. New York: Psychological Corporation 1992.

[19] Ravens J. Manual for Raven's Progressive Matrices and Vocabulary Scales, Section 3.Standard Progressive Matrices. London: H.K. Lewis and Co; 1987.

[20] Nikolopoulos D, Goulandris N, Hulme C, Snowling M. The cognitive bases of learning to read and spell in Greek: evidence from a longitudinal study. J Exp Child Psychol 2006; 94: 1-17.

[21] Elliot CD, Murray DJ, Pearson LS. British abilities scales. Windsor: NFER Nelson 1983.

[22] Semel E, Wiig EH, Secord W. Clinical Evaluation of Language Fundamentals-Revised. Examiners Manual. The Psychological Corporation, USA: Harcourt Brace \& Company, Publishers 1987.

[23] American Psychiatric Association. Diagnostic and statistical manual of mental disorders. $4^{\text {th }}$ ed. Washington DC: Author 2000. 
[24] Freud S. The interpretation of dreams. The standard edition of the complete psychological works of sigmund freud, 4-5. Updated in Beyond Pleasure Principle 1900/1920; 15: 273-338.

[25] Siegel A. Dreams that can change your life: navigating life's passages through turning points dreams. New York: Putnam 1996.

[26] Orner RJ, Stolz P. Making sense of repetition phenomena by integrating psychotraumatology and psychodynamic psychotherapy. J Trauma Stress 2002; 15(6): 465-71.

[27] Freud S. Beyond the pleasure principle. the standard edition of the complete psychological works of sigmund freud NY: Nation 1920/1993; vol. 18: pp. 7-64.

[28] Lansky MR, Bley CR. Post-traumatic Nightmares: Psychodynamic Explorations. USA: Analytic Press 1995.

[29] Siegel A, Bulkeley K. Dreamcatching: Every parent's guide to exploring and understanding children's dreams and nightmares. New York: Random House 1998.

[30] Golse B. Cauchemars, rêves et processus de pensée. Psychiatr Enfant 1992; 37(2): 395-413.

[31] Houzel D. Rêve et psychopathologie de l'enfant. Neuropsychiatr Enfance Adolesc 1980; 28: 155-64.

[32] Blom GE. Panel Reports: The Role of the Dream in Child Analysis. J Am Psychoanal Assoc 1960; 8: 517-25.
[33] Barrett D. Trauma and Dreams. Cambridge: Harvard University Press 1996.

[34] Dermitzaki I, Efklides A. Aspects of self-concept and their relationship with language performance and verbal reasoning ability. Am J Psychol 2000; 113(4): 621-38.

[35] Kloomok S, Cosden M. Self-concept in children with learning disabilities: the relationship between global self-concept, academic 'discounting', nonacademic self-concept and perceived social support. Learn Disabil Q 1994; 17: 140-53.

[36] PDM Task Force. Psychodynamic Diagnostic Manual: A guide to the classification of adult and child mental disorders. Silver Spring, MD: Alliance of Psychoanalytic Associations 2006.

[37] Kris E. The recoveries of childhood memories in psychoanalysis. Psychoanal Stud Chil 1956; 11: 132-28.

[38] Ferenczi S. Confusion of tongues between adults and the child: The language of tenderness and of passion. Contemp Psychoanal 1968; 24: 196-206.

[39] Greenacre P. The influence of psychic trauma on genetic patterns. In: Furst S, Ed. Psychic Trauma. New York: Basic Books 1967.

Received: March 31, 2014

Revised: June 10, 2014

Accepted: June 13, 2014

(C) Nikolopoulos \& Chatira; Licensee Bentham Open.

This is an open access article licensed under the terms of the Creative Commons Attribution Non-Commercial License (http://creativecommons.org/licenses/by-nc/3.0/) which permits unrestricted, non-commercial use, distribution and reproduction in any medium, provided the work is properly cited. 